\title{
Distributed Solution of Road Lighting Problem Over Multi-Agent Networks
}

\author{
DOnur CIHAN \\ Marmara University, Faculty of Engineering, Department of Electrical and Electronics Engineering; \\ onur.cihan@marmara.edu.tr; https://orcid.org/0000-0002-5729-2417; +90 2167773673
}

Received 7 April 2020; Revised 15 May 2020; Accepted 21 May 2020; Published online 28 August 2020

\begin{abstract}
In this study, we consider the solution of the road lighting problem by distributed algorithms over multi-agent networks where the objective is to determine the powers of the lamps that provide the desired road lighting level for a given road profile. The road is modeled as multiple road sections each with a length of 50 meters where a lighting pole is located in the middle of each section. Under given assumptions, the illumination levels of the road sections are expressed as linear functions of the powers of the lamps. When the processing units in the lighting poles can communicate wirelessly with the neighboring processing units and make simple calculations, it is shown that the power levels of the lamps that provide the desired lighting level for each road section can be calculated in a distributed manner. Finally, the model and the proposed solution has been verified by a numerical example.
\end{abstract}

Keywords: multi-agent systems, distributed algorithms, distributed control, road illumination

\section{Yol Aydınlatma Probleminin Çok Etmenli Ağlarda Dağıtık Çözümü}

\section{Öz}

Bu çalışmada, verilen bir yol profili için yol aydınlatma düzeyinin istenilen değerlerde olmasını sağlayan lamba güçlerini belirleme probleminin çok etmenli sistemler üzerinde tanımlanan bir algoritma ile dağıtık çözümü ele alınmıştır. Söz konusu yol, ellişer metrelik uzunluğa sahip bölümler halinde modellenmiş ve her bir bölümün ortasında bir aydınlatma direği konumlandırılmıştır. Yapılan varsayımlar altında yol bölümlerinin aydınlanma düzeyleri, lambaların güçlerinin bir doğrusal fonksiyonu olduğu ifade edilmiştir. Aydınlatma direklerinde bulunan işlem birimlerinin kendilerine yakın olan direklerdeki işlem birimleriyle haberleşebildiği ve basit hesaplamalar yapabildiği durumda, yolun istenilen bir aydınlık seviyesine sahip olabilmesi için gerekli olan lamba gücü seviyelerinin, dağıtık olarak hesaplanabildiği gösterilmiş ve sayısal sonuçlar ile modelin ve çözümün geçerliği doğrulanmıştır.

Anahtar Kelimeler: çok etmenli sistemler, dağıtık algoritmalar, dağıtık kontrol, yol aydınlatması

\section{Giriş}

Yolun yeterli ve doğru bir şekilde aydınlatılması, güvenli bir gece sürüşü için büyük öneme sahiptir. İstatistiklere göre doğru bir şekilde aydınlatılmamış bir yolda meydana gelen kaza oranı, gündüz meydana gelen kaza oranının üç katıdır [1]. Bunun yanı sıra, yolda seyir halinde bulunan araçların sürücülerinin konforlu bir sürüş deneyimi yaşayabilmeleri için, yolun aydınlık seviyesinin belirli bir değer aralığında ve parıltı dağılımının homojene olabildiğince yakın olması istenmektedir [2]. Yol aydınlatmasının iyi olmadığı yerlerde yapılacak doğru bir aydınlatma ile trafik kazaları kayda değer oranda azaltılabilmektedir. Bu amaçla otoyol aydınlatma lambalarının konumlandırılmaları ve bu lambaların güçlerinin doğru şekilde ayarlanması büyük önem arz etmektedir.

Yol aydınlatma problemi, belirli varsayımlar altında bir doğrusal denklem olarak ifade edilebilmekte ve istenilen bir aydınlık seviyesini sağlayan lamba gücü değerleri bu denklemin çözümü olarak hesaplanabilmektedir. Ancak yolun belirli kısımlarının farklı düzeyde aydınlatılması istendiğinde, bu yeni denklem sisteminin çözülerek uygun lamba güçlerinin tekrar hesaplanması gerekmektedir. Bu 
çalışmada, işlem birimleri ile güçleri kontrol edilebilen lambalara sahip bir otoyolun, istenilen aydınlık seviyesini sağlayacak şekilde, lamba güçlerini dağıtık olarak hesaplama mekanizması incelenmiştir. Bu amaçla, doğrusal denklem sistemlerinin çözümü için yeni bir yaklaşım olan ve çok etmenli sistemlerde kullanılan bir dağıtık algoritmadan yararlanılmıştır.

Literatürde doğrusal denklem sistemlerinin çözümü, araştırmacıların üzerinde çok uzun zamandır çalışılmakta olduğu ve birçok farklı mühendislik uygulamasında karşıllaşılan önemli bir problemdir. Bu amaçla Jacobi yöntemi, Gauss-Seidel yöntemi, Kaczmarz yöntemi gibi birçok klasik algoritma başarı ile geliştirilmiştir [3]. Bu algoritmaların ortak özelliği, denklem sisteminin tamamının bilindiği varsayımına sahip olmalarıdır ve bu nedenle merkezileştirilmiş algoritmalar olarak adlandırılırlar. Ancak kısmi türevli diferansiyel denklemler [4], hesaplamalı akışkanlar dinamiği [5], elektromanyetik hesaplamaları [6], güç sistemleri tahminlemesi [7] ve arama motorları için geliştirilen pagerank algoritmaları [8] gibi birçok pratik uygulamada denklem sistemindeki bilinmeyen sayısı çok fazladır ve merkezileştirilmiş algoritmaların bu denklem sistemlerini çözmesi pratik değildir. Bunun yanında, doğrusal denklem sistemini oluşturan denklemler birbirinden çok farklı fiziksel konumlarda ortaya çıkabileceği için merkezileştirilmiş bir algoritmanın kullanılabilmesi için tüm denklemlerin merkezi işlemci tarafından tek bir yerde toplanması gerekmektedir.

Merkezileştirilmiş algoritmaların aksine, dağıtık algoritmalar çok fazla değişken sayısına sahip doğrusal denklem sistemlerinin çözümü için iyi bir alternatif olması nedeniyle son 10 yılda araştırmacılar tarafından çalışılmaktadır [7, 9-22]. Bu dağıtık algoritmalar, denklem sisteminin yalnızca bir kısmını içeren birden fazla sayıda alt sisteme ayırmakta ve her alt sistemin çok etmenli sistemleri oluşturan bir etmen tarafından ele alındığı ve komşu etmenlerle bilgi paylaşımı yaparak tüm denklem sisteminin çözümünü bulmalarını sağlamaktadır. Mou ve ark. tarafindan, etmenlerin komşularıyla kendi alt sistemleri için ürettikleri çözümü paylaştıkları, komşularının çözümlerini de kullanarak çözümlerini güncelledikleri ve nihayetinde denklem sisteminin tamamına çözüm buldukları bir dağıtık algoritma önerilmiştir [9]. Bu algoritmanın başarısının ardından, ayrık zamanda [10-16] ve sürekli zamanda [1721] benzer bilgi paylaşım kısıtları altında birçok algoritma geliştirilmiştir. Geliştirilen bu algoritmaların temel çalışma mantığı, her bir etmenin denklem sisteminin bir alt kümesine çözüm üretirken, komşu etmenlerin denklemleri ile çözümlerinde oydaşım (konsensüs) sağlamaya çalışmalarıdır [22]. Denklem sisteminin katsayılar matrisinin seyrek matris olması durumunda etmenler arası bilgi paylaşımının daha etkin bir şekilde yapıldığı bir dağıtık algoritma [10]'da verilmiş̧tir. Algoritmaların başlangıç çözümünün, denklem alt sistemini sağlayan bir çözüm olmak zorunda olmadığı, keyfi bir başlangıç vektörü seçimi ile denklem sisteminin çözülmesini sağlayan bir algoritma ise [11]'de önerilmiştir.

Literatürde önerilen algoritmaların birç̧oğu, doğrusal denklem sisteminin tek çözümü olduğu durumda çözümü bulmayı amaçlamaktadırlar. Ancak bir denklem sisteminin sonsuz çözümünün olması veya çözümsüz olması durumu da söz konusudur. Denklem sisteminin sonsuz çözümünün olduğu durumda en küçük Öklid normuna sahip olan çözümün bulunabilmesini sağlayan algoritmalar [11,12]'de geliştirilmişken, denklem sisteminin çözümü olmadığı durumda etmenlerin en küçük karesel hatayı sağlayan çözümü bulmasını sağlayan algoritmalar $[13,17]$ 'de verilmiştir.

Bu makalede, verilen herhangi bir otoyol profili için istenilen aydınlık düzeyini sağlayacak olan lamba güçlerinin belirlenmesi problemi -literatürde yer alan merkezileştirilmiş hesaplama yöntemlerinden farklı olarak- çok etmenli ağlar üzerinden doğrusal denklem sistemlerinin çözümü için tasarlanmış dağıtık bir algoritma kullanılarak çözülmüştür. Önerilen sistemin genel işleyişi Şekil 1'de gösterilmiştir. Aydınlatma direklerinde kablosuz iletişim yeteneğine sahip olan akıllı lambaların her biri, iletişim menzilinde bulunan komşu lambalardan gelen lamba gücü kestirimlerini de kullanarak dağıtık bir algoritma yardımıyla yolda istenilen aydınlık seviyesine ulaşmak için gerekli lamba güçleri hesabını günceller ve komşu lambalarla paylaşır. Bu güncellemeler sonucunda, tüm akıllı lambalar istenilen aydınlık seviyesine ulaşmak için gerekli olan tüm lamba güçlerini belirler ve lamba gücünü ayarlayarak yolu istenildiği şekilde aydınlatabilir. 


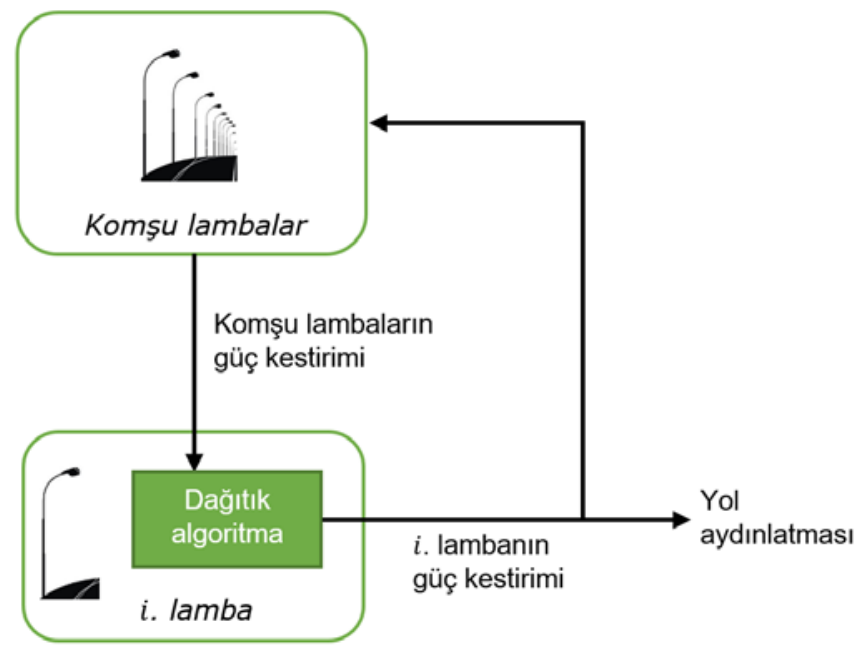

Şekil 1 Akıllı yol aydınlatma sisteminin işleyişi

Makalenin geri kalanı şu şekilde düzenlenmiştir. Bölüm 2'de çok etmenli bir sistemde tanımlanmış akıllı yol aydınlatma modeli verilmiş ve bu problemin dağıtık olarak çözülebilmesi için kullanılabilecek bir algoritma tanıtılmıştır. Bu algoritmanın yol aydınlatma probleminin çözümündeki başarımı Bölüm 3'te detayları verilen benzetim çalışmaları ile gösterilmiştir. Bölüm 4'te ise, makalede elde edilen sonuçlar yorumlanarak gelecek çalışmalardan bahsedilmiştir.

\section{Akıllı Yol Aydınlatma Modeli}

Bu bölümde, birden fazla lamba ile aydınlatılan bir otoyola ait yol bölümlerinin aydınlık seviyelerinin lamba güçlerinin doğrusal bir fonksiyonu olduğu gösterilerek bu problemin çözülebilmesi için çok etmenli sistemler üzerinde tanımlanan dağıtık bir algoritmanın detayları verilmiştir.

\subsection{Akıllı Yol Aydınlatma Sisteminin Çok Etmenli A $\breve{g}$ Modeli}

$\mathrm{Bu}$ bölümde, bir yola ait farklı eğimlere sahip yol bölümlerinin birden fazla lamba tarafindan aydınlatılmasının doğrusal bir denklem sistemi şeklinde modellenmesinden bahsedilmiştir. Bu amaçla, örnek bir yol aydınlatma sistemi Şekil 2'de gösterilmiştir. Şekilde yol bölümlerinin aydınlık seviyeleri $y_{i}(i=1, \ldots, n)$ ve lamba güçleri $p_{j}(j=1, \ldots, n)$ olarak temsil edilmekte olup; $\alpha_{i j}$ ifadesi $j$. lambadan çıkan ışığın $i$. yol bölümünün normali ile yaptığı açıyı belirtmektedir. $d_{i j}$ ise $j$. lamba ile $i$. yol bölümünün merkezi arasındaki mesafedir.

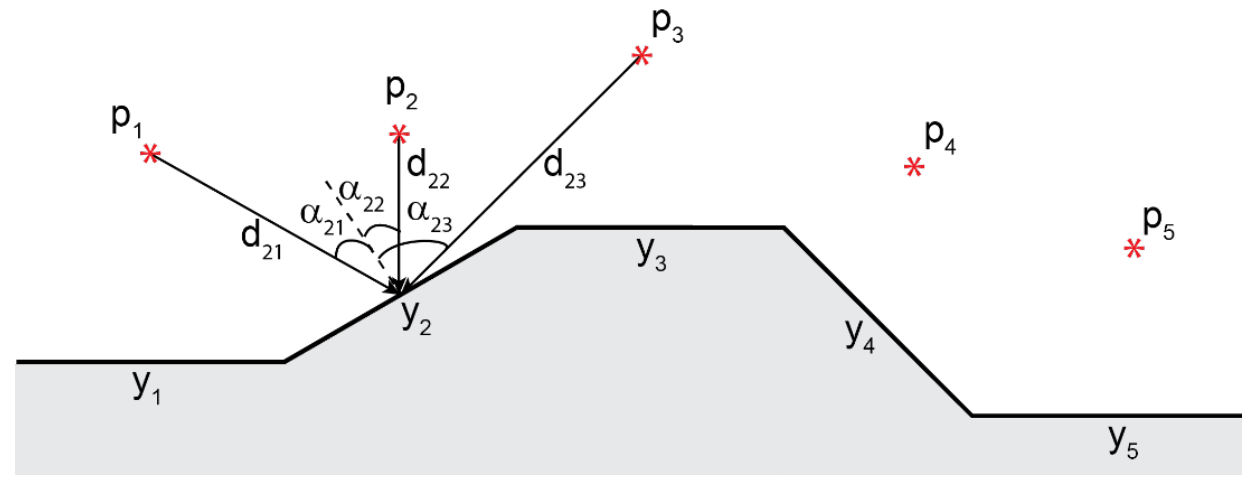

Şekil 2 Bir yol bölümünün birden fazla lamba ile aydınlatılması

Bu tanımlamalar kullanılarak, $j$. lambanın $i$. yol bölümünün aydınlık seviyesine katkısı 


$$
a_{i j}=\left\{\begin{array}{cl}
\frac{p_{j} \cos \left(\alpha_{i j}\right)}{d_{i j}^{2}} & , \text { eğer } j . \text { lamba } i . \text { yol bölümünü doğrudan aydınlatabiliyorsa } \\
0 & , \text { diğer durumlarda }
\end{array}\right.
$$

olarak ifade edilebilir. Birden fazla lamba tarafından aydınlatılan i. yol bölümünün aydınlık seviyesi

$$
y_{i}=\sum_{j=1}^{n} a_{i j} p_{j}
$$

denklemi ile ifade edilebilir. Yolların toplam aydınlık seviyeleri $y=\left[y_{1}, y_{2}, \ldots, y_{n}\right]^{\top}$ ve lambaların güçleri $p=\left[p_{1}, p_{2}, \ldots, p_{n}\right]^{\top}$ vektörleri tanımlanarak,

$$
y=A p
$$

doğrusal denklemi elde edilir. Bu denklemde yer alan $A=\left[a_{i j}\right]$, elemanları negatif olmayan ve $n \times n$ boyutlarında bir matristir. Yol aydınlatma probleminin çözülebilmesi için, $y=A p$ denklemini sağlayan

$$
p^{*}=A^{-1} y
$$

vektörünün hesaplanması gerekmektedir.

Yorum 1: Denklem 4'te yer alan $p^{*}$ çözümünün hesaplanabilmesi için son 10 yıla kadar literatürdeki algoritmaların temel varsayımı $A$ matrisinin tüm satıllarının bir merkezi işlemci tarafından biliniyor olmasıdır. Ancak yol aydınlatma probleminden de görüleceği gibi, bazı mühendislik uygulamalarında $A$ matrisinin bazı satırları ve $y$ vektörünün aynı satırlara karşılık gelen elemanları fiziksel olarak birbirinden çok uzak konumlarda ortaya çıkabilmektedir. Bu nedenle her bir yol bölümünün istenilen aydınlatma düzeyine sahip olabilmesi için gerekli olan lamba güçlerini belirleyebilme problemi, dağıtık olarak çok etmenli sistemler üzerinde tanımlanarak çözülebilir.

\subsection{Dağıtık Çözüm Algoritması}

Bölüm 1'de bahsedildiği üzere doğrusal denklem sistemlerinin çözümü konusunda son yıllarda çeşitli algoritmalar geliştirilmiştir. Bu algoritmalar, sürekli ya da ayrık zamanda tanımlı olmasına; başlangıç çözümünün yerel denklem sistemini sağlamak zorunda olup olmamasına ve çözüm olmadığ durumda en küçük kareler çözümünü elde edebiliyor olup olmamasına göre farklı sınıflara ayrılmaktadır. Bölüm 2.1 'de açıklanan yol aydınlatma probleminin çok etmenli sistemler yardımıyla çözümü için gerekli tanımlar ve dağıtık algoritma bu bölümde verilmiştir.

Etmenler arası iletişimin iki yönlü olarak sağlandığı ve $n>1$ adet etmenden oluşan birçok etmenli sistemi ele alalım. $V=\{1,2, \ldots, n\}$ köşeler kümesi ve $E \subset V \times V$ kenarlar kümesi olmak üzere, çok etmenli sistem $G=(V, E)$ çizgesi ile temsil edilebilir. Eğer $i$. etmenden $j$. etmene bir bilgi akışı mevcut ise bu durumda $(i, j) \in E$ 'dir ve $i$. etmen ile $j$. etmen komşu etmenlerdir. Bir $i$ etmeninin komşular kümesi $N_{i}=\{j:(j, i) \in E\}$ olarak tanımlanır ve $i$. etmeninin komşu sayısı $\left|N_{i}\right|$ olarak ifade edilebilir. Eğer ağda bulunan her $i$ ve $j$ etmeni arasında doğrudan veya dolaylı bir iletişim mevcut ise, bu ağ çizgesine kuvvetli bağlı çizge adı verilir. Her bir aydınlatma lambasının gücünün bir işlem birimi tarafından kontrol edildiği ve işlem birimleri arasında kablosuz iletişimin mevcut olduğu durumda, aydınlatma lambaları etmen olarak tanımlanarak yol aydınlatma problemi çok etmenli sistemde tanımlanabilmektedir.

Ağı temsil eden çizgenin kuvvetli bağlı olduğu ve ağdaki etmenlerin bildikleri $y=A p$ denkleminin alt kümelerinin birleşiminin $y=A p$ denklemine eşit olduğu durumda, keyfi başlangıç vektörlerinden başlayarak doğrusal denklem sisteminin eşsiz çözümüne ulaşabildikleri dağıtık bir algoritma Wang ve ark. tarafindan 


$$
p_{i}(k+1)=P_{n u l l\left(A_{i}\right)} \sum_{j \in N_{i}} w_{i j} p_{j}(k)+A_{i}^{\top}\left(A_{i} A_{i}^{\top}\right)^{-1} y_{i} \quad(i=1, \ldots, n)
$$

olarak önerilmiştir [12]. Burada $p_{i}(k)$ değeri $k$. adımda $i$. etmenin çözüm vektörünü temsil ederken, $w_{i j}$ parametresi $j$. etmenden $i$. etmene gelen çözüm vektörünün çarpıldığı katsayıdır ve

$$
w_{i j} \begin{cases}>0 & , \text { eğer }(\mathrm{j}, \mathrm{i}) \in \mathcal{E} \text { ise } \\ =0 & \text {, diğer durumlarda }\end{cases}
$$

olarak tanımlanmaktadır. Bir $i$ etmeninin komşu çözümlerini ağırlıklandırmak için kullandığı katsayılar

$$
\sum_{j \in N_{i}} w_{i j}=1 \quad(i=1, \ldots, n)
$$

denklemi sağlanacak şekilde seçilmelidir. $A_{i}$ matrisi, $i$. etmen tarafından bilinen $y_{i}=A_{i} p_{i}$ denkleminin katsayılar matrisidir. $P_{\text {null }\left(A_{i}\right)}$ matrisi ise $A_{i}$ 'nin sıfır uzayına iz düşüm matrisidir ve

$$
P_{\text {null }\left(A_{i}\right)}=I-A_{i}^{\top}\left(A_{i} A_{i}^{\top}\right)^{-1} A_{i} \quad(i=1, \ldots, n)
$$

denklemi ile hesaplanmaktadır [22]. Denklem 5'te verilen dağıtık algoritmanın sözde kod yapısı Tablo 1 'de verilmiştir.

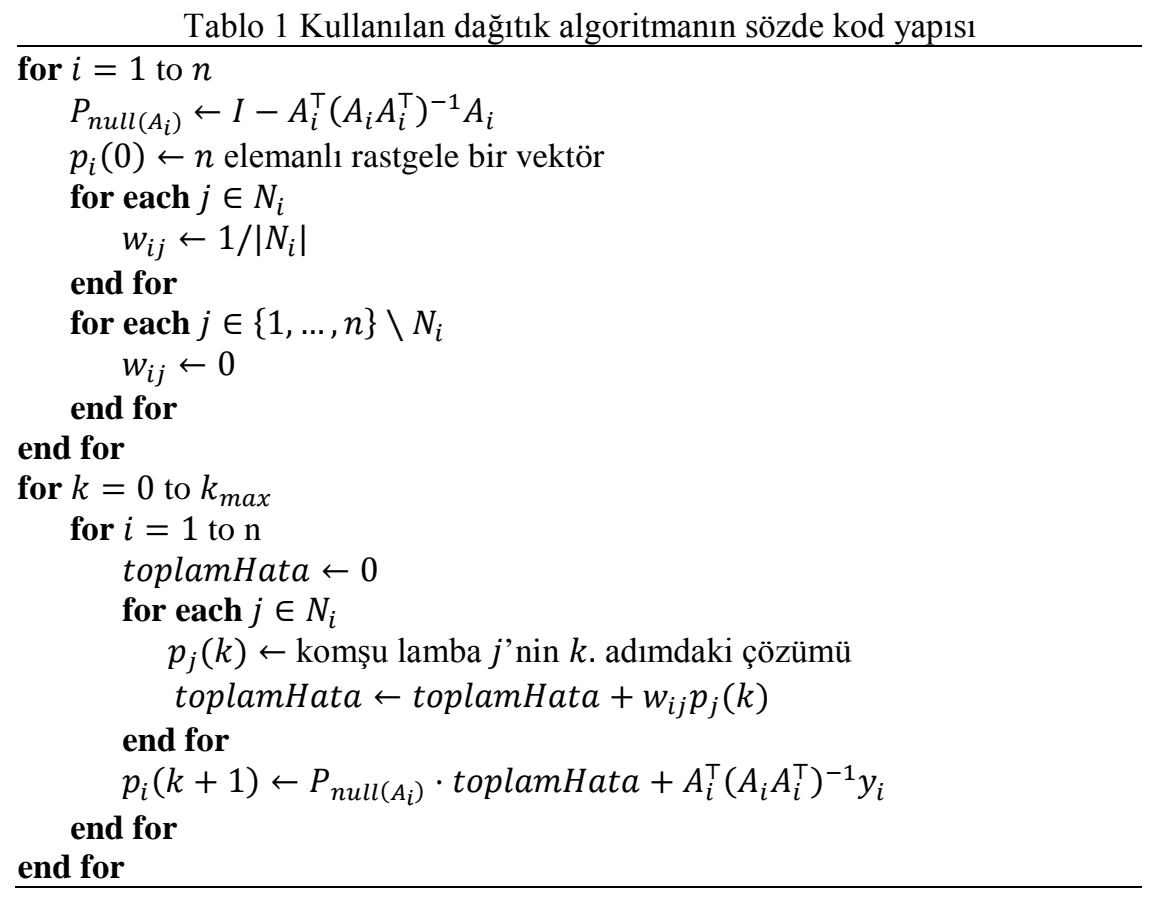

Yorum 2: Etmenlerin Denklem 5 'te verilen algoritmayı kullanabilmesi için öncelikle $P_{\text {null }\left(A_{i}\right)}$ matrisini hesaplamaları gerekmektedir. Yol aydınlatma probleminin doğası gereği, $y=A p$ denklem sisteminin her bir denklemi farklı bir fiziksel konumda ortaya çıkmaktadır ve etmenlerin bildikleri $y_{i}=A_{i} p_{i}$ denklemlerinde bulunan $A_{i}$ matrisleri tek satırdan oluşmaktadır. Bu nedenle $A_{i} A_{i}^{\top}$ sayıl bir değerdir ve $P_{n u l l\left(A_{i}\right)}$ 'nin hesabı için yüksek işlem gücü gerekmemektedir.

\section{Benzetim Çalışmaları}

Bu bölümde, Bölüm 2.1'de detayları açıklanan yol aydınlatma probleminin Bölüm 2.2’deki algoritma ile çözümünü gösterebilmek için GNU Octave benzetim ortamında yapılan çalışmalardan bahsedilmiştir [23]. Bu amaçla, 750 metre uzunluğunda ve (otoyol aydınlatma standartlarına uygun olarak) ellişer metre aralıklarla aydınlatılmak istenen bir otoyol ele alınmıştır. Benzetim çalışmaları için kullanılacak 
olan yol bölümleri doğrusal olarak modellenmiş olup, eğimleri bir önceki yol eğiminden $\pm \% 3$ 'ten fazla değişmeyecek şekilde ve yol eğimi hiçbir zaman $\pm \% 6$ 'yı geçmeyecek şekilde rastgele oluşturulmuştur. Yol profili Şekil 3’te ve yol bölümlerine ait eğim değerleri Tablo 2'de verilmiştir.

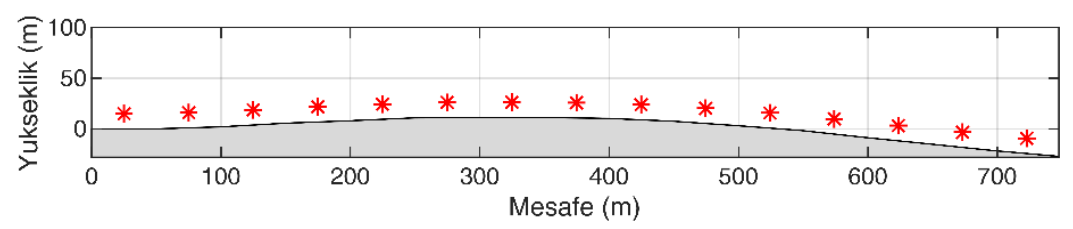

Şekil 3 Oluşturulan örnek yol profili

Tablo 2 Benzetim çalışmalarında kullanılan yol bölümlerinin eğim değerleri

\begin{tabular}{|c|c|c|c|c|c|c|c|c|c|c|c|c|c|c|c|}
\hline $\begin{array}{c}\text { Yol } \\
\text { bölümü }\end{array}$ & 1 & 2 & 3 & 4 & 5 & 6 & 7 & 8 & 9 & 10 & 11 & 12 & 13 & 14 & 15 \\
\hline $\begin{array}{c}\text { Ĕ̆im } \\
\text { (\%) }\end{array}$ & 0 & 0,53 & $-1,11$ & $-1,80$ & $-1,31$ & $-2,79$ & $-4,04$ & $-3,34$ & $-4,74$ & $-2,80$ & 0,09 & 1,47 & 0,54 & 1,04 & $-1,31$ \\
\hline
\end{tabular}

Her yol bölümü, yolun ortasına yerleştirilmiş ve standartlara uygun olarak 15 metre yükseklikteki bir aydınlatma direğinde bulunan bir lamba ile aydınlatılmak istendiği durumda, lambalar ve yol bölümlerinin orta noktaları arasındaki mesafelerin değerleri Tablo 3’teki gibi olmaktadır.

Tablo 3 Lambalar ile yol bölümlerinin orta noktaları arasındaki mesafeler (m)

\begin{tabular}{|c|c|c|c|c|c|c|c|c|c|c|c|c|c|c|c|}
\hline Yol bölümü & 1 & 2 & 3 & 4 & 5 & 6 & 7 & 8 & 9 & 10 & 11 & 12 & 13 & 14 & 15 \\
\hline 1 & 15,00 & 52,48 & 101,65 & 151,38 & 201,22 & 251,05 & 300,84 & 350,63 & 400,35 & 449,96 & 499,54 & 549,02 & 598,49 & 648,07 & 697,75 \\
\hline 2 & 51,91 & 15,00 & 53,00 & 101,97 & 151,58 & 201,28 & 250,98 & 300,73 & 350,41 & 399,99 & 449,55 & 499,03 & 548,51 & 598,10 & 647,79 \\
\hline 3 & 100,52 & 51,38 & 15,00 & 53,06 & 101,95 & 151,44 & 201,05 & 250,75 & 300,42 & 350,00 & 399,57 & 449,08 & 498,59 & 548,21 & 597,94 \\
\hline 4 & 150,02 & 100,24 & 51,32 & 15,00 & 52,95 & 101,73 & 151,14 & 200,78 & 250,42 & 300,01 & 349,60 & 399,14 & 448,70 & 498,37 & 548,13 \\
\hline 5 & 199,81 & 149,89 & 100,27 & 51,44 & 15,00 & 52,65 & 101,36 & 150,84 & 200,43 & 250,01 & 299,63 & 349,20 & 398,80 & 448,51 & 498,32 \\
\hline 6 & 249,72 & 199,77 & 149,99 & 100,46 & 51,72 & 15,00 & 52,26 & 101,07 & 150,50 & 200,03 & 249,65 & 299,25 & 348,89 & 398,63 & 448,47 \\
\hline 7 & 299,71 & 249,75 & 199,93 & 150,26 & 100,82 & 52,15 & 15,00 & 52,06 & 100,75 & 150,09 & 199,65 & 249,25 & 298,91 & 348,68 & 398,54 \\
\hline 8 & 349,71 & 299,75 & 249,92 & 200,19 & 150,57 & 101,16 & 52,34 & 15,00 & 51,66 & 100,28 & 149,69 & 199,25 & 248,92 & 298,71 & 348,59 \\
\hline 9 & 399,69 & 349,73 & 299,91 & 250,17 & 200,51 & 150,93 & 101,45 & 52,73 & 15,00 & 51,15 & 99,88 & 149,30 & 198,93 & 248,72 & 298,61 \\
\hline 10 & 449,61 & 399,67 & 349,87 & 300,16 & 250,50 & 200,89 & 151,27 & 101,89 & 53,21 & 15,00 & 50,86 & 99,53 & 149,00 & 198,75 & 248,62 \\
\hline 11 & 499,49 & 449,57 & 399,80 & 350,13 & 300,50 & 250,89 & 201,23 & 151,69 & 102,32 & 53,51 & 15,00 & 50,48 & 99,23 & 148,83 & 198,66 \\
\hline 12 & 549,30 & 499,40 & 449,68 & 400,04 & 350,46 & 300,87 & 251,22 & 201,64 & 152,10 & 102,64 & 53,85 & 15,00 & 50,25 & 99,15 & 148,82 \\
\hline 13 & 599,09 & 549,21 & 499,53 & 449,94 & 400,40 & 350,85 & 301,22 & 251,63 & 202,03 & 152,41 & 102,95 & 54,08 & 15,00 & 50,30 & 99,24 \\
\hline 14 & 648,92 & 599,06 & 549,42 & 499,88 & 450,37 & 400,84 & 351,22 & 301,62 & 251,99 & 202,28 & 152,61 & 103,05 & 54,03 & 15,00 & 50,43 \\
\hline 15 & 698,80 & 648,97 & 599,35 & 549,83 & 500,35 & 450,84 & 401,21 & 351,60 & 301,94 & 252,18 & 202,41 & 152,64 & 102,96 & 53,91 & 15,00 \\
\hline
\end{tabular}

Lamba direklerine yerleştirilmiş olan, basit hesaplamalar yapabilen ve haberleşme yeteneğine sahip işlem birimleri vasıtasıyla, tüm yol bölümlerinin homojen olarak aydınlatılması amaçlanmaktadır. Benzetim çalışmalarında kablosuz haberleşme menzillerinin 50 ile 100 metre arasında olduğu varsayılmakta olup, her bir etmen yalnızca kendisine komşu olan etmenler ile haberleşebilmektedir. $\mathrm{Bu}$ durumda çok etmenli ağ, Şekil 4’te verilen çizge ile temsil edilebilir.

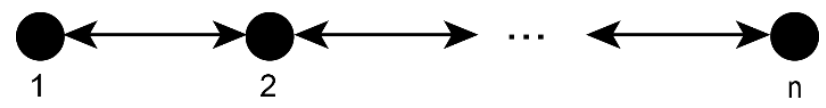

Şekil 4 Etmenlerin menzillerinin 50 ile 100 metre arası olduğu durumda etmenler arası iletişimi temsil eden çizge

Yol bölümlerinin tamamının 8 lux seviyesinde aydınlatılması istendiği durum için $y=[8, \ldots, 8]^{\top}$ olarak seçilmiştir. Lambaların yol bölümlerini doğrudan aydınlatıp aydınlatmadığ 1 benzetim ortamında 
hesaplanarak $A_{i}$ matrisleri oluşturulmuş ve etmenlerin başlangıç değerleri $p_{i}(1)=[0, \ldots, 0]^{\top}$ olarak (yanmayan lamba) ve ağırlık katsayıları $w_{i j}=1 /\left|N_{i}\right|$ şeklinde seçilerek Denklem 5 'te verilen algoritma kullanılarak dağıtık olarak çözüm elde edilmiştir. Örnek bir etmenin (7. etmen) çözümünün zamana bağlı değişimi Şekil 5'teki gibi olmaktadır. Şekilden de görüleceği gibi, çözüm fonksiyonu denklem sisteminin eşsiz çözümü olan ve Tablo 4 'te verilen değerlere asimptotik olarak yakınsamıştır.

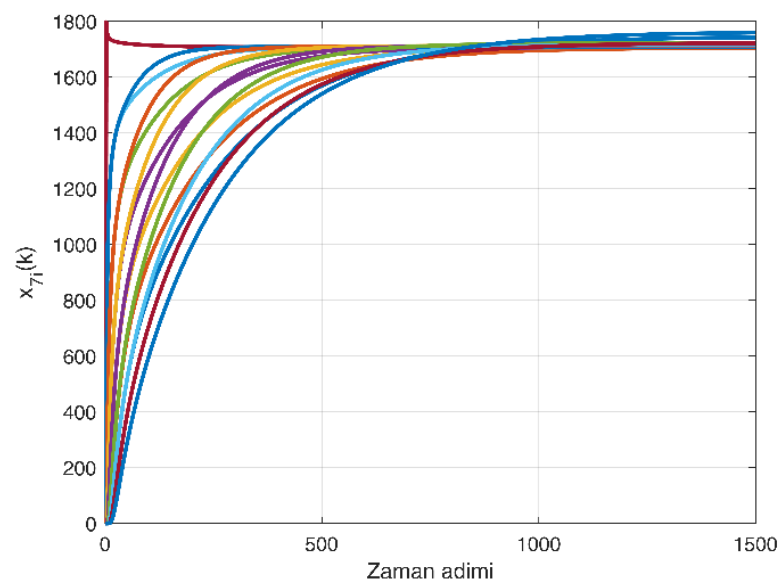

Şekil 5 Yedinci etmenin (lambanın), istenilen aydınlatma seviyelerine ulaşılması için gerekli lamba gücü seviyelerini dağıtık olarak hesabı

Tablo 4 Benzetim çalışmalarında incelenen yol aydınlatma probleminin eşsiz çözümü

\begin{tabular}{|c|c|c|c|c|c|c|c|c|c|c|c|c|c|c|c|}
\hline Yol bölümü & 1 & 2 & 3 & 4 & 5 & 6 & 7 & 8 & 9 & 10 & 11 & 12 & 13 & 14 & 15 \\
\hline $\begin{array}{c}\text { Lamba } \\
\text { gücü }\end{array}$ & 1746 & 1706 & 1709 & 1707 & 1710 & 1709 & 1708 & 1710 & 1712 & 1713 & 1714 & 1722 & 1719 & 1723 & 1764 \\
\hline
\end{tabular}

Tüm etmenlerin denklem sistemini çözdüğünü göstermek amacıyla, etmenlerin çözümlerindeki hataların normlarının toplamını ifade eden

$$
h(k)=\sum_{i=1}^{n}\left\|p_{i}(k)-p^{*}\right\|
$$

fonksiyonunun zamanla değişimi Şekil 6'da verilmiştir. $h(k)$ 'nin asimptotik olarak sıfıra yakınsaması tüm etmenlerin denklem sistemini çözdüğünü, yani istenilen yol aydınlık seviyelerine ulaşabilmek için her bir lambanın sahip olması gereken güç değerini belirleyebildiğini göstermektedir. Her bir etmen, bağlı olduğu lambanın gücünü bu çözümden elde ettiği değere göre ayarlandığında homojen yol aydınlatması sağlanabilmektedir.

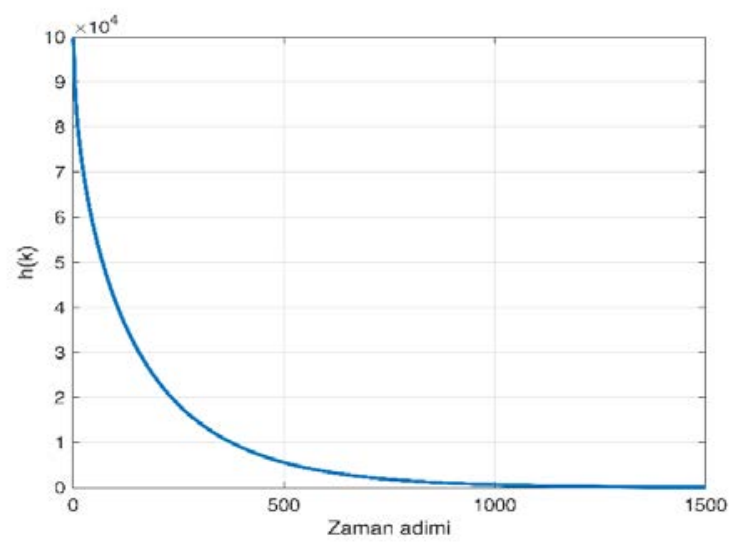

Şekil 6 Etmenlerin gerekli lamba güçleri seviyesini hesabındaki toplam hata normlarının $(h(k))$ zamanla değişimi 
Etmenler denklem sistemini yinelemeli olarak çözerken, her zaman adımında elde ettikleri çözümleri kullanarak lamba güçlerini ayarladığında, yol bölümlerinin aydınlık seviyesinin zamana bağlı değişimi Şekil 7'de gösterildiği gibi olmaktadır $\left(S_{i}(k), i\right.$. yol bölümünün $k$. zaman adımındaki aydınlık seviyesini temsil etmektedir).

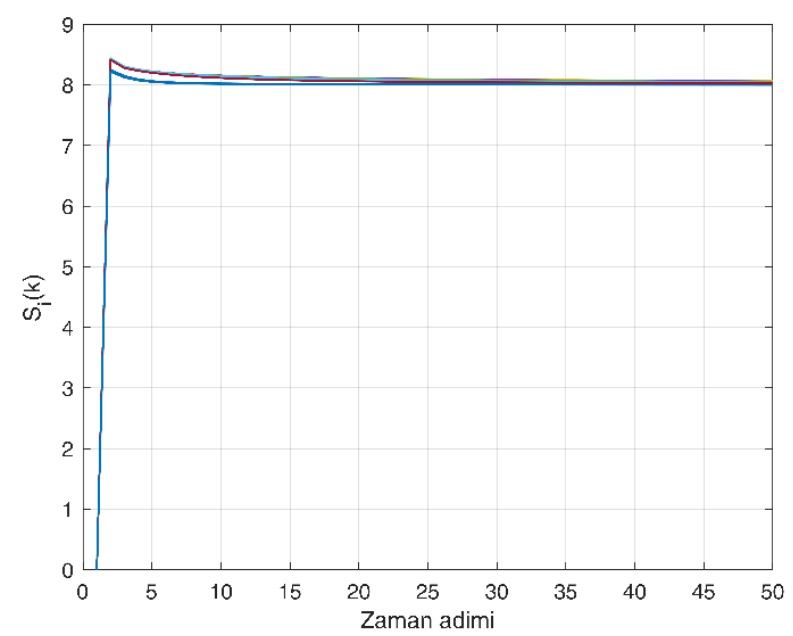

Şekil 7 Etmenler elde ettikleri çözüm vektörlerini kullanarak lamba güçlerini ayarladıklarında, yol aydınlık seviyelerinin zamana bağlı değişimi

Yorum 3: Şekil 7'den de görüleceği gibi istenilen aydınlık seviyesine ulaşmak için gerekli süre, Şekil 6 'da gösterilen denklem sisteminin tamamının çözümü için gerekli süreden çok daha azdır. Bunun nedeni, $i$. etmenin denklem sistemini çözerken elde ettiği çözüm vektörünün $i$. elemanının ( $i$. lambanın gücünün) gerçek çözümdeki değerine diğer elemanlardan çok daha hızlı yakınsamasıdır.

\section{Sonuçlar ve Gelecek Çalışmalar}

Otoyolun ellişer metre aralıklarla aydınlatıldığı ve yol eğiminin ellişer metre aralıklarla değiştiği varsayımı altında, yolun homojen olarak aydınlatılabilmesi için gerekli olan lamba güçlerinin belirlenmesi problemi doğrusal bir denklem sistemi şeklinde modellenmiştir. Her bir lambanın, bağlı oldukları ve kablosuz iletişim yeteneğine sahip basit işlem birimleri vasıtası ile güç ayarı yapabildiği sistem için, işlem birimlerinin kendilerine yakın olan diğer işlem birimleri ile bilgi paylaşımı yaparak tüm denklem sistemini (dolayısı ile gerekli olan tüm lamba güçlerini) dağıtık bir algoritma kullanarak çözebildikleri gösterilmiştir. Bulunan bu çözümler işlem birimleri tarafından kullanılarak lamba güçleri ayarlandığında, otoyolda istenilen aydınlatma seviyesine ulaşmanın mümkün olduğu yapılan benzetim çalışmaları ile doğrulanmıştır. Bulunan lamba gücü değerlerinin her lamba için farklı çıkması, homojen yol aydınlatması için lambaların farklı güçlerde aydınlatma sağlaması gerektiğini göstermektedir. Gelecek çalışmalarda, otoyollarda daha yaygın olarak kullanılan refüjden çift konsollu aydınlatma sistemi için problem modelinin geliştirilerek, uygulamaya yönelik pratik sonuçlar elde edilmesi planlanmaktadır.

\section{Teșekkür}

Bu çalışma TÜBİTAK Proje No: 117E204 tarafından desteklenmiştir.

\section{Referanslar}

[1] H. Jin, S. Jin, L. Chen, S. Cen and K. Yuan, "Research on the Lighting Performance of LED Street Lights With Different Color Temperatures," IEEE Photonics Journal, vol. 7, no. 6, pp. 19, 2015. 
[2] C. Sun, X. Lee, I. Moreno, C. Lee, Y. Yu, T. Yang and T. Chung, "Design of LED Street Lighting Adapted for Free-Form Roads," IEEE Photonics Journal, vol. 9, no. 1, pp. 1-13, 2017.

[3] W. Hackbusch, Iterative Solution of Large Sparse Systems of Equations, New York, USA:Springer-Verlag, 1994.

[4] M. Krstic and A. Smyshlyaev, Boundary Control of PDEs: A Course on Backstepping Designs, Philadelphia, USA:SIAM Publishing, 2008.

[5] J. Anderson, Computational Fluid Dynamics: The Basics With Applications, New York, USA:Mc-Graw-Hill Education, 1995.

[6] B. Carpentieri, I. Duff, L. Giraud and M. Magolu monga Made, "Sparse Symmetric Preconditioners for Dense Linear Systems in Electromagnetism," Numerical Linear Algebra with Applications, vol. 11, pp. 753-771, 2004.

[7] F. Pasqualetti, R. Carli and F. Bullo, "Distributed Estimation via Iterative Projections With Application to Power Network Monitoring," Automatica, vol. 48, no. 5, pp. 747-758, 2012.

[8] D. Silvestre, J. Hespanha and C. Silvestre, "A Pagerank Algorithm Based on Asynchronous Gauss-Seidel Iterations," Proc. - 2018 American Control Conference, pp. 484-489, 2018.

[9] S. Mou, J. Liu and A.S. Morse, "A Distributed Algorithm for Solving a Linear Algebraic Equation," IEEE Transactions on Automatic Control, vol. 60, no. 11, pp. 2863-2878, 2015.

[10] J. Liu, S. Mou and A.S. Morse, "Asynchronous Distributed Algorithms for Solving Linear Algebraic Equations," IEEE Transactions on Automatic Control, vol. 63, no. 2, pp. 372-385, 2018.

[11] J. Liu, A.S. Morse, A. Nedic and T. Başar, "Exponential Convergence of a Distributed Algorithm for Solving Linear Algebraic Equations," Automatica, vol. 83, pp. 37-46, 2017.

[12] X. Wang, J. Zhou, S. Mou and M.J. Corless, "A Distributed Linear Equation Solver for Least Square Solutions," Proc. - 56th IEEE Conference on Decision and Control, pp. 5955-5960, 2017.

[13] J. Liu, X. Gao and T. Başar, "A Communication-Efficient Distributed Algorithm for Solving Linear Algebraic Equations," Proc. - 7th International Conference on Network Games, Control and Optimization, pp. 62-69, 2014.

[14] P. Wang, W. Ren and Z. Duan, "Distributed Algorithm to Solve a System of Linear Equations With Unique or Multiple Solutions From Arbitrary Initializations," IEEE Transactions on Control of Network Systems, vol. 6, no. 1, pp. 82-93, 2018.

[15] X. Wang, S. Mou and D. Sun, "Improvement of a Distributed Algorithm for Solving Linear Equations," IEEE Transactions on Industrial Electronics, vol. 64, no. 4, pp. 3113-3117, 2017.

[16] S. Mou, Z. Lin, L. Wang, D. Fullmer and A.S. Morse, "A Distributed Algorithm for Efficiently 
Solving Linear Equations and its Applications," Systems \& Control Letters, vol. 91, pp. 21-27, 2016.

[17] B.D.O. Anderson, S. Mou, A.S. Morse and U. Helmke, "Decentralized Gradient Algorithm for Solution of a Linear Equation," Numerical Algebra, Control \& Optimization, vol. 6, no. 3, pp. 319-328, 2016.

[18] G. Shi, B.D.O. Anderson and U. Helmke, "Network Flows That Solve Linear Equations," IEEE Transactions on Automatic Control, vol. 62, no. 6, pp. 2659-2674, 2017.

[19] M. Yang and C.Y. Tang, "A Distributed Algorithm for Solving General Linear Equations Over Networks," Proc. - 54th IEEE Conference on Decision and Control, pp. 3580-3585, 2015.

[20] J. Liu, X. Chen, T. Başar ve A. Nedic , "A Continuous-Time Distributed Algorithm for Solving Linear Equations," Proc. - 2016 American Control Conference, pp. 5551-5556, 2016.

[21] Y. Liu, C. Lageman, B.D.O. Anderson and G. Shi, "An Arrow-Hurwicz-Uzawa Type Flow as Least Squares Solver for Network Linear Equations," Automatica, vol. 100, pp. 187-193, 2019.

[22] P. Wang, S. Mou, J. Lian and W. Ren, "Solving a System of Linear Equations: From Centralized to Distributed Algorithms," Annual Reviews in Control, vol. 47, pp. 306-322, 2019.

[23] GNU Octave, “GNU Octave,” 2020. [Online]. Available: https://www.gnu.org/software/ octave/. [Accessed: 15-May-2020]. 